\title{
The Future of Gas Infrastructures in Eurasia
}

\author{
Ger Klaassen \\ Alan McDonald \\ International Institute for Applied Systems Analysis \\ Jimin Zhao \\ Kennedy School of Government, Harvard University, Cambridge, MA, USA \\ RR-01-08 \\ May 2001
}

Reprinted from Energy Policy 29 (2001) 399-413. 
Research Reports, which record research conducted at IIASA, are independently reviewed before publication. Views or opinions expressed herein do not necessarily represent those of the Institute, its National Member Organizations, or other organizations supporting the work.

Reprinted with permission from Energy Policy 29 (2001) 399-413.

Copyright (c) 2001 Elsevier Science Ltd.

All rights reserved. No part of this publication may be reproduced or transmitted in any form or by any means, electronic or mechanical, including photocopy, recording, or any information storage or retrieval system, without permission in writing from the copyright holder. 


\title{
The future of gas infrastructures in Eurasia
}

\author{
Ger Klaassen $^{\mathrm{a}, *}$, Alan McDonald ${ }^{\mathrm{a}}$, Jimin Zhao ${ }^{\mathrm{b}}$ \\ anternational Institute for Applied Systems Analysis, Schlossplatz-1 A-2361, Laxenburg, Austria \\ ${ }^{\mathrm{b}}$ Kennedy School of Government, Harvard University, 79 John F. Kennedy Street, Cambridge, USA
}

Received 6 July 2000

\begin{abstract}
The IIASA-WEC study global energy perspectives emphasized trends toward cleaner, more flexible, and more convenient final energy forms, delivered chiefly by energy grids, and noted potential energy infrastructure deficiencies in Eurasia. We compare planned interregional gas pipelines and LNG terminals in Eurasia with the study's projected trade flows for 2020. We focus on the study's three high-growth scenarios and single middle course scenario. The comparison indicates that high gas consumption in a scenario need not imply high gas trade. For the former Soviet Union, a robust strategy across all six scenarios is to implement existing plans and proposals for expanding gas export capacity. For Eastern Europe, significant import capacity expansions beyond current plans and proposals are needed in all but the middle course scenario. Western European plans and proposals need to be increased only in two high gas consumption scenarios. Planned and proposed capacities for the Middle East (exports) and centrally planned Asia (imports) most closely match a high gas trade scenario, but are otherwise excessive. Paradoxically, for the Pacific OECD, more short-term import capacity is needed in scenarios with low gas consumption than in high-consumption scenarios. For Southeast Asia, proposed import capacities are significantly higher than scenario trade projections. (C) 2001 Elsevier Science Ltd. All rights reserved.
\end{abstract}

Keywords: Gas; Infrastructure; Eurasia

\section{Introduction}

The IIASA-WEC ${ }^{1}$ study global energy perspectives emphasized, first, a persistent and pervasive trend in consumer demand toward cleaner, more flexible, and more convenient final energy forms, chiefly delivered by energy grids (Nakićenović et al., 1998). Second, it identified Asia, particularly China and South Asia, as the likely world leaders in energy consumption growth, and drew attention to potentially important energy infrastructure deficiencies in Eurasia.

The purpose of this paper is to compare existing, planned, and proposed Eurasian infrastructures for natural gas transport, i.e., pipelines and LNG facilities, to interregional trade flows in the six IIASA-WEC scenarios. We address two questions: (1) How well do current plans and proposals match each of the scenarios? (2) Are

\footnotetext{
${ }^{*}$ Corresponding author. Tel.: + 43-2236-807; fax: + 43-2236-807488.

E-mail address: klaassen@iiasa.ac.at (G. Klaassen).

${ }^{1}$ IIASA: International Institute for Applied Systems Analysis. WEC: World Energy Council.
}

there robust strategies that are attractive across all six scenarios?

The paper has the following structure. Section 2 describes gas production, gas consumption, and gas trade flows under the IIASA-WEC scenarios. Section 3 reviews planned and proposed gas pipelines and LNG facilities in Eurasia. Section 4 compares projected interregional gas export and import capacities with those resulting from the IIASA-WEC scenarios. Section 5 concludes and discusses the results.

\section{Gas consumption and trade flows in the IIASA-WEC scenarios}

\subsection{Introduction}

Eurasia includes seven of the eleven regions defined in the IIASA-WEC study. These are, as shown in Fig. 1, Pacific OECD (PAO), Centrally planned Asia and China (CPA), South Asia (SAS), Other Pacific Asia (PAS), Newly independent states of the Former Soviet Union (FSU), Central and Eastern Europe (EEU), and Western Europe (WEU). This section consists of three parts. First, it 
introduces the six scenarios of the IIASA-WEC study. Second it examines energy demand and supply for Eurasia. Finally, it looks at gas consumption and production as well as gas trade flows in Eurasia under the different scenarios.

\subsection{The global outlook}

The six IIASA-WEC scenarios are divided into three cases. Case A presents a future of impressive technological improvements and consequent high economic growth. Case B describes a future with less ambitious, though perhaps more realistic, technological improvements, and consequently more intermediate economic growth. Case C presents a "rich and green" future. It includes both substantial technological progress and unprecedented international cooperation, including major resource transfers from North to South centered specifically on environmental protection and international equity. These are driven by explicit policies, including carbon taxes, to reduce global carbon emissions in 2100 to two gigatons of carbon $(\mathrm{GtC})$, one-third the level of global emissions in 1990. Key characteristics of the three cases are given in Table 1.

Technology parameters were varied within Case A to produce three scenarios, and within Case $\mathrm{C}$ to produce two scenarios, as follows. In Scenario A1, investments and technological progress focus on oil and gas, and the future availability of oil and gas resources is relatively high. As a result the dominance of oil and gas is perpetuated to the end of the 21 st century. At the other end of the spectrum, Scenario A2 assumes oil and gas resources to be scarce and investments and technological progress to favor coal. The result is a massive return to

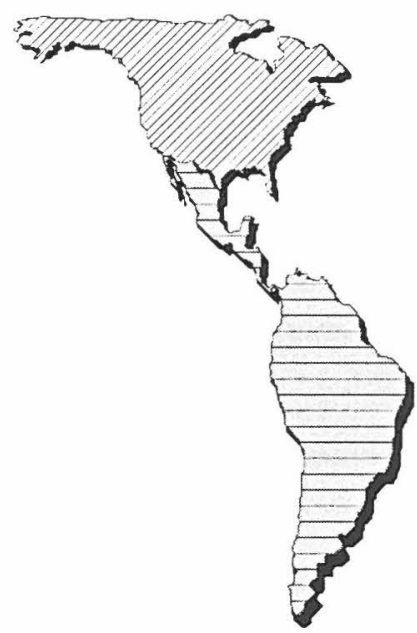

1 NAM North America

2 LAM Latin America and the Caribbean

3 AFR Sub-Saharan Africa

4 MEA Middle East and North Africa

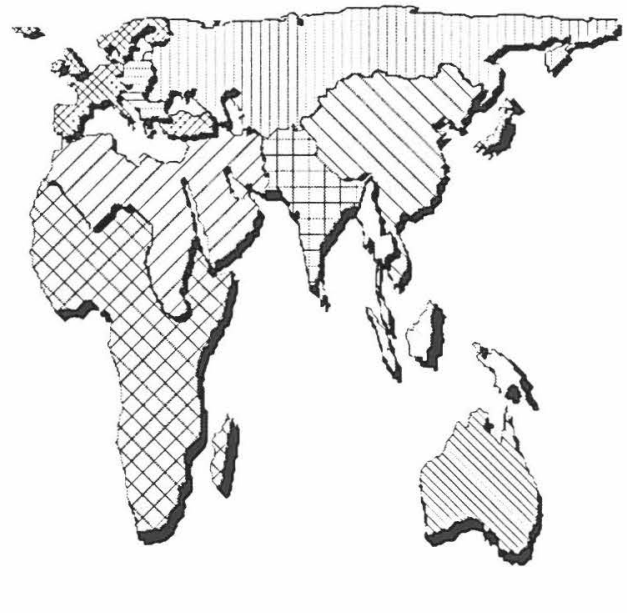

OECD

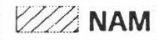

QXX. WEU

SIV PAO

REFS
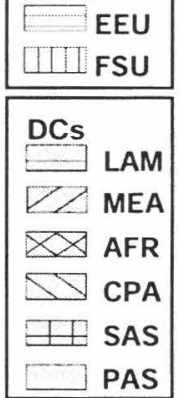

5 WEU Western Europe

6 EEU Central and Eastem Europe

9 SAS South Asia

7 FSU Newly independent states of

the former Soviet Union

8 CPA Centrally planned Asia and China
10 PAS Other Pacific Asia

11 PAO Pacific OECD

Fig. 1. IIASA-WEC study regions. Countries are divided among regions as follows. NAM: Canada, Guam, Puerto Rico, United States of America, and Virgin Islands. LAM: Antigua and Barbuda, Argentina, Bahamas, Barbados, Belize, Bermuda, Bolivia, Brazil, Chile, Colombia, Costa Rica, Cuba, Dominica, Dominican Republic, Ecuador, El Salvador, French Guyana, Grenada, Guadeloupe, Guatemala, Guyana, Haiti, Honduras, Jamaica, Martinique, Mexico, Netherlands Antilles, Nicaragua, Panama, Paraguay, Peru, Saint Kitts and Nevis, Santa Lucia, Saint Vincent and the Grenadines, Suriname, Trinidad and Tobago, Uruguay, and Venezuela. AFR: Angola, Benin, Botswana, British Indian Ocean Territory, Burkina Faso, Burundi, Cameroon, Cape Verde, Central African Republic, Chad, Comoros, Côte d'Ivoire, Congo, Djibouti, Equatorial Guinea, Eritrea, Ethiopia, Gabon, Gambia, Ghana, Guinea, Guinea-Bissau, Kenya, Lesotho, Liberia, Madagascar, Malawi, Mali, Mauritania, Mauritius, Mozambique, Namibia, Niger, Nigeria, Reunion, Rwanda, Sao Tome and Principe, Senegal, Seychelles, Sierra Leone, Somalia, South Africa, Saint Helena, Swaziland, Tanzania, Togo, Uganda, Zaire, Zambia, and Zimbabwe. MEA: Algeria, Bahrain, Egypt (Arab Republic), Iraq, Iran (Islamic Republic), Israel, Jordan, Kuwait, Lebanon, Libya/SPLAJ, Morocco, Oman, Qatar, Saudi Arabia, Sudan, Syria (Arab Republic), Tunisia, United Arab Emirates, and Yemen. WEU: Andorra, Austria, Azores, Belgium, Canary Islands, Channel Islands, Cyprus, Denmark, Faeroe Islands, Finland, France, Germany, Gibraltar, Greece, Greenland, Iceland, Ireland, Isle of Man, Italy, Liechtenstein, Luxembourg, Madeira, Malta, Monaco, Netherlands, Norway, Portugal, Spain, Sweden, Switzerland, Turkey, and United Kingdom. EEU: Albania, Bosnia and Herzegovina, Bulgaria, Croatia, Czech Republic, The former Yugoslav Rep. of Macedonia, Hungary, Poland, Romania, Slovak Republic, Slovenia, and Yugoslavia. FSU: Armenia, Azerbaijan, Belarus, Estonia, Georgia, Kazakhstan, Kyrgyzstan, Latvia, Lithuania, Republic of Moldova, Russian Federation, Tajikistan, Turkmenistan, Ukraine, and Uzbekistan. CPA: Cambodia, China, Hong Kong, Korea (DPR), Lao (PDR), Mongolia, and Vietnam. SAS: Afghanistan, Bangladesh, Bhutan, India, Maldives, Nepal, Pakistan, and Sri Lanka. PAS: American Samoa, Brunei Darussalam, Fiji, French Polynesia, GilbertKiribati, Indonesia, Malaysia, Myanmar, New Caledonia, Papua New Guinea, Philippines, Republic of Korea, Singapore, Solomon Islands, Taiwan, China, Thailand, Tonga, Vanuatu, and Western Samoa. PAO: Australia, Japan, and New Zealand. 
Table 1

Summary of the three IIASA-WEC cases in 2050 and 2100 compared with 1990 (GWP = gross world product, Gtoe = gigatons oil equivalent, and $\mathrm{GtC}=$ gigatons of carbon). Source: Nakićenović et al. (1998)

\begin{tabular}{|c|c|c|c|}
\hline & \multicolumn{3}{|l|}{ Case } \\
\hline & $\begin{array}{l}\text { A } \\
\text { High growth }\end{array}$ & $\begin{array}{l}\text { B } \\
\text { Middle course }\end{array}$ & $\begin{array}{l}\text { C } \\
\text { Ecologically driven }\end{array}$ \\
\hline \multicolumn{4}{|l|}{ Population, billion } \\
\hline 1990 & 5.3 & 5.3 & 5.3 \\
\hline 2050 & 10.1 & 10.1 & 10.1 \\
\hline 2100 & 11.7 & 11.7 & 11.7 \\
\hline \multicolumn{4}{|l|}{ GWP, trillion US(1990)\$ } \\
\hline 1990 & 20 & 20 & 20 \\
\hline 2050 & 100 & 75 & 75 \\
\hline 2100 & 300 & 200 & 220 \\
\hline $\begin{array}{l}\text { Global primary energy intensity improvement, } \\
\text { percent per year }\end{array}$ & Medium & Low & High \\
\hline 1990 to 2050 & -0.9 & -0.8 & -1.4 \\
\hline 1990 to 2100 & -1.0 & -0.8 & -1.4 \\
\hline \multicolumn{4}{|l|}{ Primary energy demand, Gtoe } \\
\hline 1990 & 9 & 9 & 9 \\
\hline 2050 & 25 & 20 & 14 \\
\hline 2100 & 45 & 35 & 21 \\
\hline \multicolumn{4}{|l|}{ Resource availability } \\
\hline Fossil & High & Medium & Low \\
\hline Non-fossil & High & Medium & High \\
\hline \multicolumn{4}{|l|}{ Technology costs } \\
\hline Fossil & Low & Medium & High \\
\hline Non-fossil & Low & Medium & Low \\
\hline \multicolumn{4}{|l|}{ Technology dynamics } \\
\hline Fossil & High & Medium & Medium \\
\hline Non-fossil & High & Medium & High \\
\hline Environmental taxes & No & No & Yes \\
\hline $\mathrm{CO}_{2}$ emission constraint & No & No & Yes \\
\hline \multicolumn{4}{|l|}{ Net carbon emissions, GtC } \\
\hline 1990 & 6 & 6 & 6 \\
\hline 2050 & $9-15$ & 10 & 5 \\
\hline 2100 & $6-20$ & 11 & 2 \\
\hline \multirow[t]{4}{*}{ Number of scenarios } & 3 & 1 & 2 \\
\hline & A1 - oil \& gas & & $\mathrm{C} 1$ - nuclear phaseout \\
\hline & A2 - coal & & $\mathrm{C} 2-$ new nuclear \\
\hline & A3 - "bio-nuke" & & \\
\hline
\end{tabular}

coal. Finally, in Scenario A3 rapid technological change in nuclear and renewable energy technologies results in a phaseout of fossil fuels for economic reasons rather than due to resource scarcity. However, natural gas proves very important as a transitional fuel in Scenario A3 - so much so that both gas use and gas trade are generally higher in Scenario A3 than even in the oil-andgas-intensive Scenario A1. In Case C, which is the most optimistic about technology and geopolitics, nuclear energy is at a crossroads, and two scenarios are included. In Scenario C1 nuclear power proves a transient technology that is eventually phased out entirely by the end of the 21 st century. In Scenario C2 a new generation of nuclear reactors is developed that is inherently safe and small scale - 100-300 megawatts electric (MWe) installed.

The differences among Scenarios A1-A3 lead to different fuel mixes (and hence different carbon emissions), but in terms of all the parameters in Table 1 except carbon emissions (e.g., economic growth, primary energy demand, and energy intensity improvements), all three Case A scenarios are identical. For Case C, the common carbon constraint means that Scenarios $\mathrm{C} 1$ and $\mathrm{C} 2$ are identical for all the parameters listed in Table 1 .

Although the improvement rates for different fossil and non-fossil energy technologies - from exploration through transport and end-use - are different in the 
different scenarios, one important feature of the gas transport market is constant across the scenarios. Gas trade in Eurasia can currently be characterized by two relatively distinct regional markets, a European or western market and an Asian Pacific or eastern market. In particular, there are currently no pipelines connecting the European and Asian Pacific markets, although LNG trade is always more flexible. The distinction, at least in terms of pipeline connections, is maintained in all six IIASA-WEC scenarios. In addition to this principal distinction into two broad regional markets it is also important to keep in mind that there are a number of important sub-markets such as Japan, Russia, Western Europe and Eastern Europe.

Turning to the scenario results, primary energy use in all six scenarios grows substantially, as shown in Table 1. The pattern of final energy use is remarkably consistent across scenarios, with all three cases reflecting a continuing pervasive shift toward energy reaching consumers in increasingly flexible, convenient, and clean forms delivered through energy grids - gas, electricity, and, in the long term, hydrogen. Concerning the structure of primary energy supply, the significant result is that there is a wide range of supply structures that can successfully match the persistent final energy trends toward convenience, cleanliness, and grids. The range of primary energy supply structures is shown in Fig. 2. Each corner of the triangle corresponds to a hypothetical situation in which all primary energy is supplied by a single category of fuels: oil and gas at the top, coal at the left, and non-fossil sources (renewables and nuclear) at the right.

Because of the long lifetimes of power plants, refineries, and other energy investments, there is not enough capital stock turnover in the scenarios prior to 2020 to allow them to diverge significantly. But after 2020 all scenarios move away from their current reliance on conventional oil and gas. This transition progresses relatively slowly in Scenario A1 where oil and gas are plentiful. In Scenario A3 and Case C, it progresses more rapidly, while in

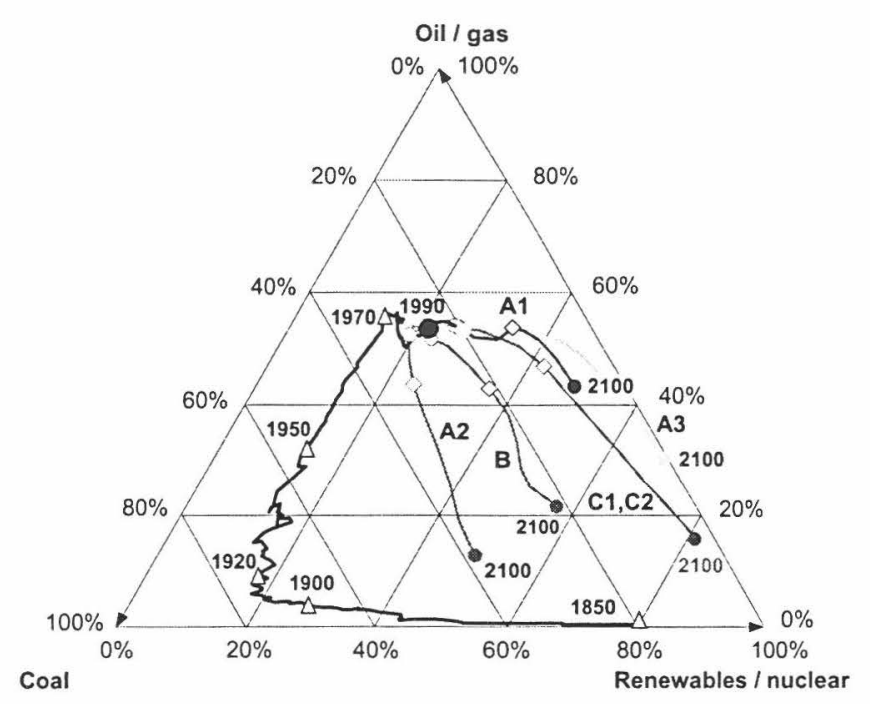

Fig. 2. Evolution of primary energy structure, shares of oil and gas, coal, and non-fossil sources, in percent, historical development from 1850 to 1990 (triangles) and in scenarios to 2020 (open circles), 2050 (diamonds), and 2100 (closed circles).

Scenario A2 and Case B, the transition away from oil and gas includes an important contribution from coal, whose long-term market share after 2050 ranges between 20 and $40 \%$. Nonetheless, little of this coal is used directly. It is instead converted to the high-quality energy carriers (electricity, liquids, and gases) demanded by the highincome consumers of the second half of the 21 st century.

Fig. 3 shows global gas consumption and interregional gas trade across the six scenarios, where "interregional" refers to trade across any of the boundaries of the eleven multi-country regions shown in Fig. 1. The term thus includes both gas that is traded across many thousands of kilometers (e.g., from Siberia to Europe) as well as gas that travels only tens or hundreds of kilometers (e.g., from Iran to Turkey, or from Libya to Italy. Scenario A3 has the highest gas consumption for all but the final time
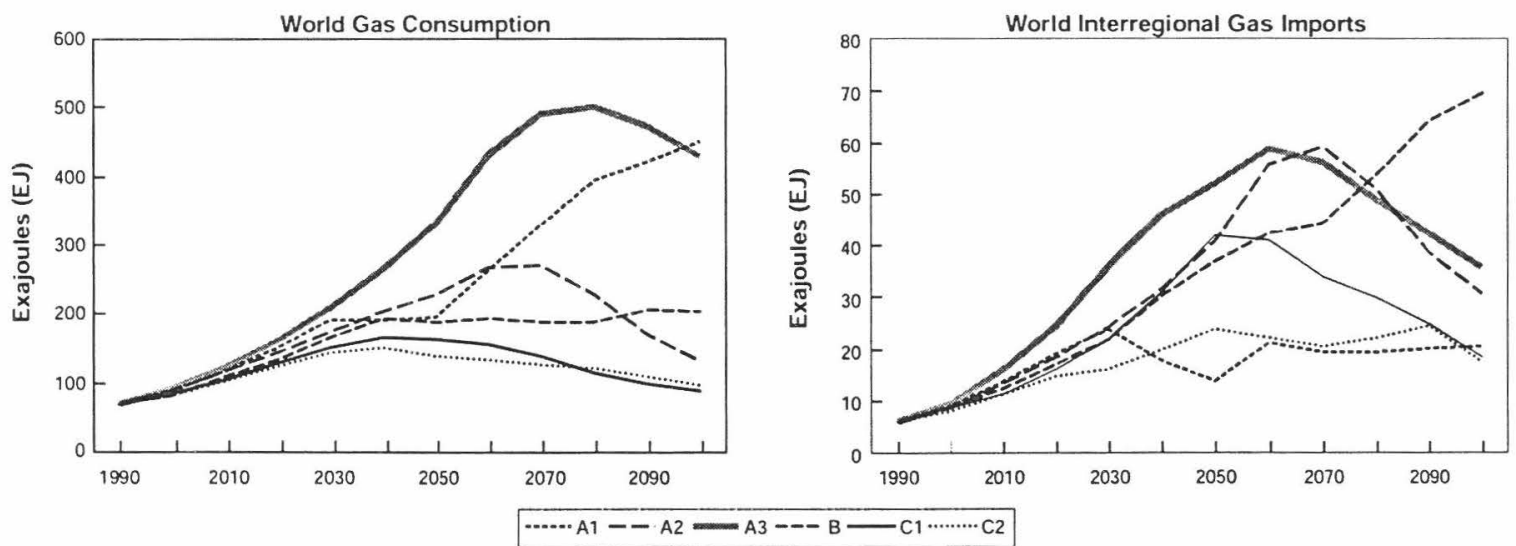

Fig. 3. World gas consumption (left) and total interregional gas imports (right) in the six IIASA-WEC scenarios. 
step in the models and also the highest, or near the highest, interregional gas imports through 2080. The dominance of gas is transitional as Scenario A3 eventually shifts to non-fossil energy sources.

High gas consumption does not always imply high trade levels. In Scenario A1 in Fig. 3, gas consumption grows steeply and steadily after 2050 and has the highest value of the six scenarios by 2100 . But throughout this 50 -year surge in gas consumption, gas trade stays essentially flat. This is because the production expansions (particularly of unconventional gas) needed to meet the surge in consumption are not all concentrated in the current exporting regions. Increased production in importing as well exporting regions, in line with Scenario A1's focus on oil and gas investments, means that increased use does not translate directly into increased imports.

Conversely, the scenario with the flattest gas consumption trajectory, Case B, leads to steadily rising interregional trade right through 2100. By 2080 Case B's gas trade is the highest of all six scenarios. Case B is a scenario with quite modest technological progress and no particular focus on gas development. The result is that there is much less of a contribution from new gas production in importing regions, and future gas production is largely from the same regions as current gas production. FSU and the Middle East and North Africa (MEA) continue as the big exporters, and Fig. 3's pattern of essentially flat global consumption after 2040 with increasing trade means export expansions in FSU and MEA are making up for declining production in other regions.

Note also that global gas trade is very similar in Scenarios A2 and A3 - i.e., in both the dirtiest (in terms of carbon emissions) and the cleanest of the study's highgrowth scenarios. But while Scenarios A2 and A3 are similar in terms of gas trade, gas consumption is much lower in the coal-intensive Scenario A2. The A2 Scenario is, in this sense, somewhat similar to Case B. Low investments in gas technologies and exploration mean little in the way of new supplies in importing regions in the second-half of the century after current prospects are exhausted. Because Scenario A2 has higher economic growth and energy demand than Case B, there is a greater need for gas as a transition fuel until technologies for converting coal to clean synfuels are perfected and widespread. But precisely because widespread use of new coal technologies is the eventual result of early coal technology investments in Scenario A2, there is less need for gas in the long run.

In this paper we focus on Cases A and B since there is currently little prospect of the large near-term North-toSouth resource transfers and purposeful preference for non-fossil fuels that is assumed to have started in 1990 in the two Case $\mathrm{C}$ scenarios. But they too are an example of divergence between gas trade and consumption. In Fig. 3,
Scenarios C1 and C2 are quite similar in terms of consumption throughout the planning horizon, but from about 2030 to 2080 gas trade is significantly higher in the nuclear-phaseout Scenario C1.

\subsection{The outlook for Eurasia}

For the five gas-importing Eurasian regions, WEU, EEU, CPA, PAO, and SAS, Fig. 4 shows consumption and imports across the IIASA-WEC scenarios. Fig. 5 shows gas consumption and exports for the two exporting Eurasian regions, FSU and PAS, and for another region, the Middle East and North Africa (MEA), much of whose gas exports go to Eurasia.

Many of the regions shown in Figs. 4 and 5 reflect the global patterns in Fig. 3. Gas consumption and trade are often highest and transitional in Scenario A3, for example, as in the global totals shown in Fig. 3. But the regional disaggregation also reinforces the point in Section 2.2 that the relationship between projected consumption and trade is not entirely straightforward.

There are two regions in Eurasian that might be called "paradox regions" because gas use and gas trade appear, in certain periods, to be inversely related. High use implies low trade and vice versa. The two regions are FSU (a gas exporting region) and PAO (a gas importing region). Fig. 5's graphs for FSU show that while gas exports rise together through 2020 in all scenarios, exports then start to drop in Scenario A3 as the scenario's early investments in gas technologies and exploration begin to take effect. The export trajectory for Scenario A1, the high-growth oil-and-gas-intensive scenario follows essentially the same pattern. This drop in exports is evidently the result of a strong preference for gas as a fuel within FSU. We know it is not because of decreased import demand elsewhere, given the surge in imports shown for Scenario A3 in the right panel of Fig. 3. As also seen in Fig. 5, MEA is the principal beneficiary of FSU's post-2020 retreat from the export market.

While Scenarios A1 and A3 present a high-consumption/low-export paradox in FSU, Case B, and to a lesser extent Scenario A2, present the opposite paradox, lowuse/high-export. In these scenarios the lack of new gas developments in importing regions and the lower priority given to gas technologies at home mean that FSU's gas resources are relatively more valuable to the region as an export commodity than as a fuel for domestic consumption. Thus gas exports and gas export revenues rise, while increases in domestic demand are largely covered by coal.

The other "paradox region" is PAO. Note that while $\mathrm{PAO}$ is a net gas-importing region, it includes one gasimporting country, Japan, one exporter, Australia, as well as New Zealand. Thus long-term projections of no net regional imports, as occur in all but Case $\mathrm{C}$ (see 

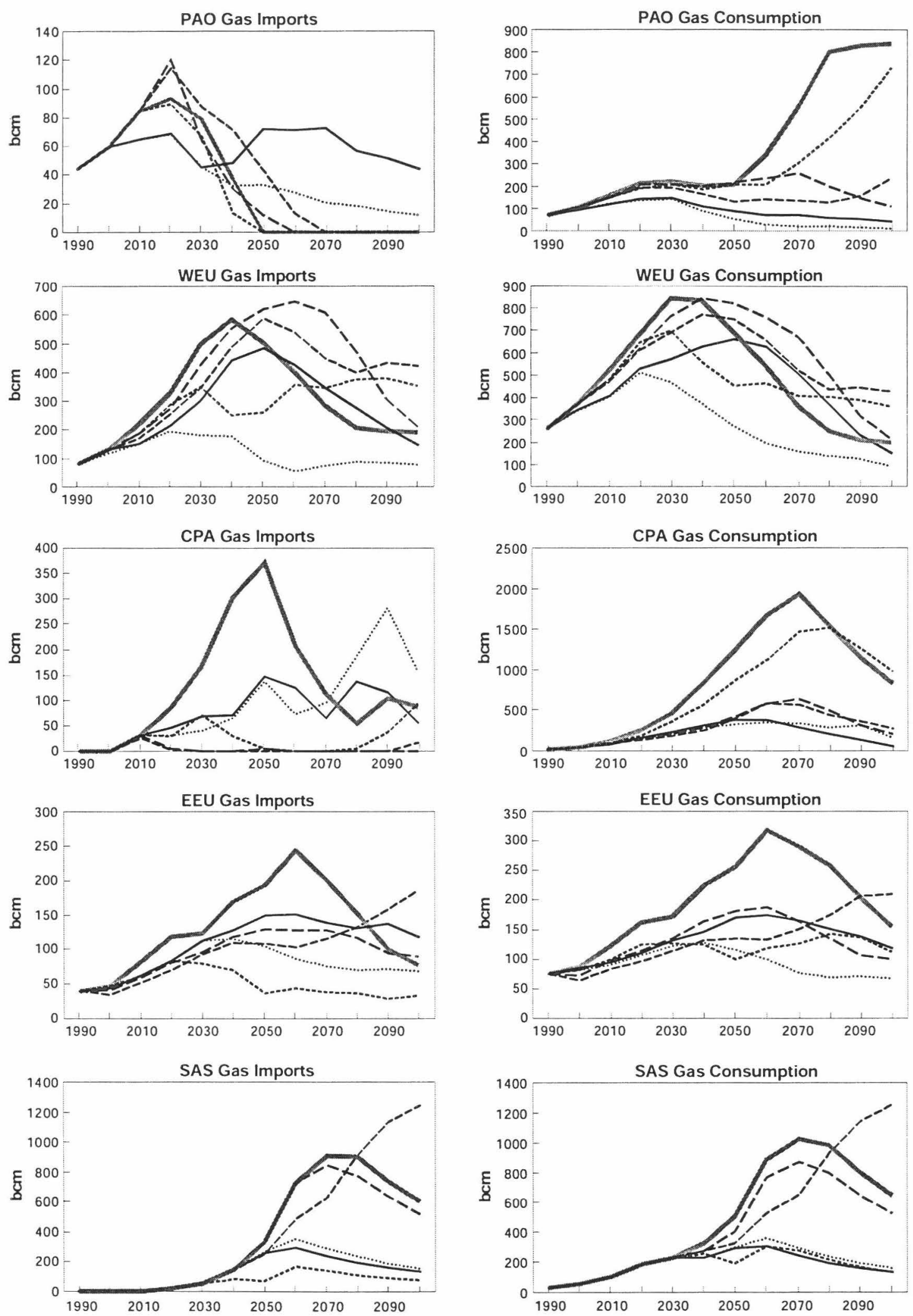

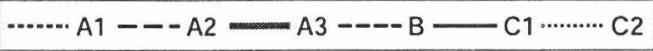

Fig. 4. Gas consumption and imports in the IIASA-WEC scenarios in five importing Eurasian regions. 

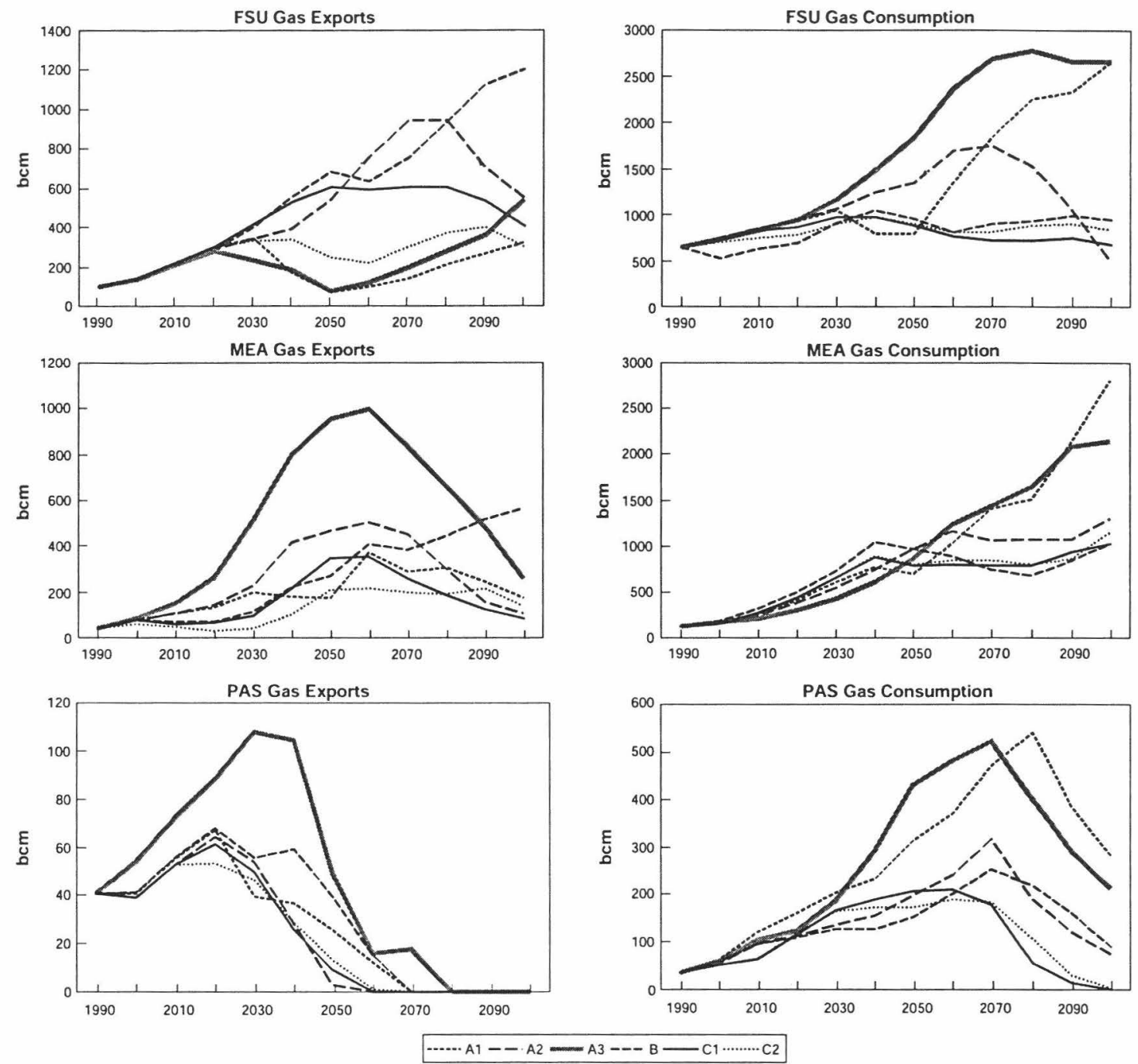

Fig. 5. Gas consumption and exports in the IIASA-WEC scenarios in two exporting Eurasian regions and MEA.

Fig. 4), may still involve significant Japanese imports and Australian exports. Paradoxical trends in gas consumption and trade are most vivid for Scenarios A1 and A3 in the long term. PAO gas consumption in both takes off in the second-half of the century, following first modest growth through 2020 and then stability until 2050 or 2060. But regional imports after 2050 drop to zero. The reason is the long-term development of particularly unconventional gas resources in the region. Conversely, Scenario A2 and Case B have the highest near-term gas import requirements, but relatively flat long-term demand trajectories.

Gas consumption and trade trends in MEA and the five Eurasian regions other than FSU and PAO are less paradoxical. High projected consumption generally corresponds to either high projected imports (WEU, EEU, CPA, and SAS) or high projected exports (PAS and MEA). For the importing regions consumption and trade are generally highest in Scenario A3, while showing a definite transitional pattern, peaking first in WEU (2040 for imports), then in CPA (2050), EEU (2060), and SAS (2070). For the other scenarios, there is more regional diversity. In the coal-intensive Scenario A2, for example, gas has almost as important a role in WEU as it has in Scenario A3. But in CPA, which has much larger coal resources, Scenario A2 means a much diminished role for gas.

Except for CPA, very long-term imports and consumption tend to be highest in Case B, where slow technological progress creates relatively little in the way of new gas supplies in the importing regions or alternative technologies and fuels. The short-term divergence in import projections (through 2020) is, in relative terms, highest in CPA and, in absolute terms, highest in WEU. There is effectively no short-term divergence in the projections for SAS, a feature of the scenarios that should probably be revisited, particularly in light of the comparison below between SAS's modest near-term imports 
as shown in Fig. 4 and more ambitious existing plans for expanding the import infrastructure.

For MEA, Scenario A3 is the most lucrative in terms of export volumes, as MEA gas exports fuel much of the transitional surge in gas use shown in Fig. 4 for all the importing regions. Domestically, MEA also makes good use of its gas resources to fuel long-term economic growth in the high-growth scenarios with faster progress in gas technologies (A1 and A3). Very long-term exports are highest in Case $\mathrm{B}$, whose slower economic growth and technological progress leaves more gas in the ground, fewer competing supplies, and fewer alternative fuel sources. PAS also cashes in on Scenario A3's transition surge in gas use through about 2040. It then uses its gas resources increasingly for its own purposes, and in the very long-term shifts to non-fossil fuels. In all other scenarios initial growth in gas exports is more modest and exports start to decline sooner - after 2020.

In presenting in this section results of the IIASA-WEC scenarios all the way out to 2100 , we recognize we have moved into a highly uncertain and somewhat speculative area. For near-term planning and investments, projections through 2020 or 2030 are much more pertinent than what might happen by 2100 . Therefore, we turn to current infrastructure plans and proposals. Nonetheless, as some of the panels in Figs. 4 and 5 show (e.g., the import decreases after 2020 in PAO), the long term may sometimes be closer than we think.

\section{Planned and proposed gas transmission infrastructures}

\subsection{Introduction}

This section reviews the past evolution and short-term prospects of international gas transmission networks in Eurasia. The focus will be on interregional gas infrastructures, i.e., those infrastructures that link one IIASA-WEC world region to another IIASA-WEC region in Eurasia. Together the seven Eurasian IIASA-WEC regions accounted for $60 \%$ of gas demand in 1990 . We will start by looking at gas transmission lines followed by a survey of LNG shipping facilities.

\subsection{The diffusion of existing gas transmission lines in Eurasia}

Currently, Eurasia can be divided in two regional gas markets. The European market ranges from North Africa through Europe up to West Siberia. WEU, EEU and FSU itself are the major consumers in this market. Major supplies come from FSU, from WEU itself (Norway, Netherlands, and United Kingdom) as well as North Africa (Algeria). The major means of transport is gas transmission pipelines. The second market is the Asian Pacific market consisting of CPA, PAS, SAS, and PAO.
The major consumer in this market is Japan (in PAO) followed by South Korea and Taiwan. In this region gas is supplied mainly as LNG. Major suppliers in 1998 were Indonesia and Malaysia (PAS). Smaller amounts were exported by Australia, Brunei, and the Middle East (Qatar and UAE) (BPAmoco, 1999).

The gas pipeline from Saratov to Moscow, a 482-mile pipeline with a capacity of 500 million cubic meters annually, constructed in 1946, is regarded as the starting point of the modern Russian and European gas industry (Petroleum Economist, 1996). In Western Europe, natural gas supply was first local and gradually reached a national scale in some countries only in the 1950s (CEDIGAZ, 1995; Stern, 1998). The discovery of the Groningen field in the Netherlands in the early 1960s, which provided gas to the Netherlands, Belgium, Germany, France, and later Italy, marked the beginning of the development of a vast network of international pipelines. In Europe, the construction of international gas transmission pipelines proceeded rapidly between 1970 and 1990 . The early 1970 s saw a period of strong growth of pipelines transporting Soviet gas into Western and Southeastern Europe (Transgas). In the mid-1970s, Norway built its first offshore pipelines from the North Sea through the Frigg and Norpipe systems to supply the United Kingdom and continental European buyers; this was the first international movement of North Sea gas to Europe. In 1980 another major pipeline (Orenburg/ Soyus) from Russia to central and east European countries was built. At the same time, the Megal line from Russia through Germany, France, and Austria was completed to transport Soviet gas to Western Europe. The Trans-Mediterranean pipeline system from Algeria to Italy, completed in 1983, provided the capacity for natural gas piping from Algeria to Western Europe. Throughout the 1980s and 1990s, major gas pipelines were built for:

- Soviet gas to Western and Eastern Europe from Urengoy (1984) and Yamburg/Progress (1988);

- Norwegian gas through the Statpipe (1986), Zeepipe I (1993), and Europipe (1995); and

- Algerian gas through the Bazoduc Maghreb-Europe (GME) line (1996) to Spain.

In the mid-1990s, pipelines were built between Britain and both parts of Ireland, and between Britain and continental Europe. The Balkan systems linking Bulgaria to Macedonia and then to Greece were completed in 1995 and 1996. Currently, the European gas market is the world's most complex in terms of the number of international participants. More than $47 \%$ of the gas consumed in Western Europe crosses at least two borders before reaching its final destination (Energy Charter, 1998).

Fig. 6 depicts the development of the total capacity of interregional gas transmission pipelines in Eurasia through mid-1999. Initial interregional exports started in 


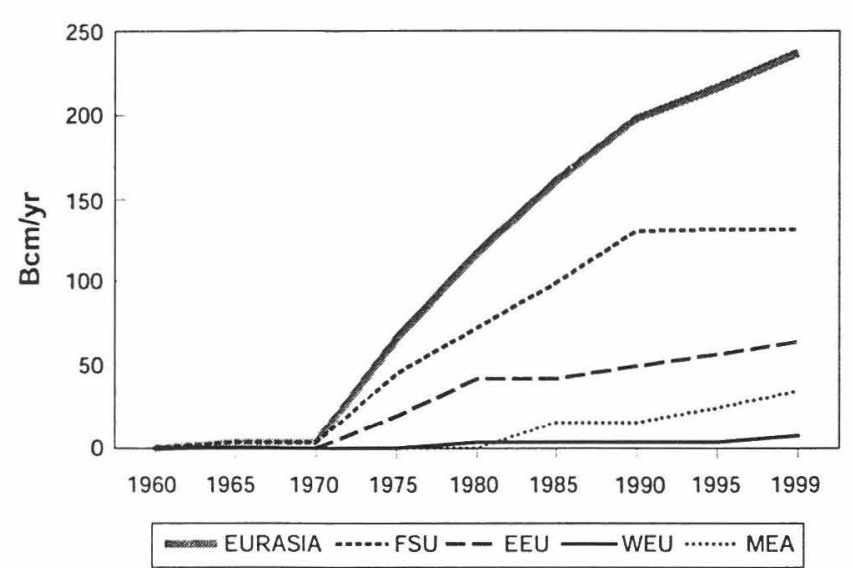

Fig. 6. The diffusion of existing interregional gas transmission pipelines in Eurasia.

Sources: CEDIGAZ (1993, 1995, 1998), IEA (1997), Nakićenović and Strubegger (1984), Stern $(1998,1999)$ and Zhao (2000).

the early 1960s with Russian gas exports to Poland. The real upsurge started in the 1970s when the export capacity of FSU increased significantly and transit capacity through the EEU increased as well. Transmission capacity from MEA (Algeria) took off in the 1980s. Total capacity is around $250 \mathrm{bcm}$ per year.

Currently, there are no interregional gas transmission lines in Asia (excluding the Asian part of FSU) and natural gas is a relatively new source of energy, averaging around $12 \%$ of total energy consumption (BPAmoco, 1999). Shipping LNG has so far been the main means of gas transportation. At present, Malaysia is the only country in the region that has initiated gas trade by pipeline. In 1992, Malaysia began to export gas by pipeline, delivering $1.5 \mathrm{bcm} /$ year of gas to Singapore through a $70 \mathrm{~km}$ long pipeline (CEDIGAZ, 1995). Countries like China, India, Indonesia, Malaysia, and Pakistan have domestic gas pipelines in place (Zhao, 2000). In China the $860-\mathrm{km}$ pipeline that transmits gas from the Ordos basin to Beijing is now the country's second longest gas pipeline (Lan and Paik, 1998). Asia's longest offshore gas pipeline is the Ya 13-1 Hong Kong pipeline, which transfers $4 \mathrm{bcm} /$ year of gas from China's Yinggehai basin to a power plant in Hong Kong.

\subsection{Proposed and planned gas transmission pipelines}

In the European part of the Eurasian gas market, the Yamal-Europe project will open a new export corridor between Russia and Western Europe, while Turkmenistan's export plans could provide new routes for gas export to Europe. The discovery of large gas reserves on the Yamal Peninsula is the basis for Russia's planned gas exports to Eastern (Poland) and Western Europe. The project consists of up to three parallel lines that will extend over $5000 \mathrm{~km}$ westward from Yamal, running across Russia, Belarus, and Poland to the German border. Turkmenistan, one of the largest gas producing countries in the world, besides exporting to present markets (the trans-Caucasian republics, Kazakhstan, Ukraine, and Russia), plans to build new gas export outlets to such areas as Pakistan, India, Western Europe, China, Japan, and Korea. In addition to building new gas pipelines, Russia and other CIS countries have to reconstruct or reinforce their existing gas pipelines and build gas storage facilities. Additional gas pipelines are proposed from Norway to European importers, and the United Kingdom has become a new gas supplier to Europe since the operation of the interconnector (Zhao, 2000). In addition, interregional gas pipelines from gasrich Russia, Turkmenistan, and the Middle East also are proposed. All planned and proposed pipelines (as of September 1999) are summarized in Table 2.

Table 2 also shows plans and proposals for the Asian Pacific region, in which proposed gas pipelines will transfer gas either from existing gas fields within the Asian regions, e.g., gas fields in Myanmar, Vietnam, Indonesia, and Malaysia, or from gas fields in Russia or Central Asia. The proposed pipelines in the Asian Pacific region are generally smaller than those in Europe, with diameters between 500 and $1000 \mathrm{~mm}$. New piped gas imports from Malaysia, Myanmar, and Indonesia are proposed to make up shortfalls in Thailand's and the Philippines' gas supplies that remain despite their recent discoveries of additional gas reserves. Singapore has sought to take a further 1 million cubic meters per day from Malaysia and to diversify supplies via pipeline from Indonesia (CEDIGAZ, 1995). If the Trans-ASEAN pipeline becomes a reality, east Malaysia could be the largest gas supplier in the Asian Pacific region. In addition to obtaining gas from this region, India and Pakistan are considering importing gas from the Middle East, while China, Japan, and Korea are planning to transport gas from Russia and Turkmenistan. In 1997, Unocal announced that Pakistan would be linked to Turkmenistan in a Central Asia Gas Pipeline project. The 1270-km pipeline would deliver up to $2 \mathrm{bcm}$ per year to Multan of Pakistan (EIA, 1998). China continues to build domestic pipelines connecting western gas producing regions to eastern gas-demand regions. In addition, two international pipelines to bring gas from Russia and Turkmenistan are proposed. Both pipelines would serve the eastern coastal region of China and possibly extend to Japan and South Korea (Zhao, 2000).

Altogether, Table 2 shows over $61,000 \mathrm{~km}$ of interregional gas transmission pipelines planned or proposed. Table 2 also includes information on the status of the projects to indicate the likelihood of their implementation: probable (very likely to happen because agreement signed and/or feasibility study completed), possible (could happen) or speculative (unlikely and little progress made). The total capacity of all projects would be at least 
Table 2

Planned/proposed interregional gas transmission lines in Eurasia ${ }^{a}$

\begin{tabular}{|c|c|c|c|c|c|}
\hline Source & Destination & Status & Region & Length $(\mathrm{km})$ & Capacity (bcm/year) \\
\hline \multicolumn{6}{|l|}{ INTERREGIONAL } \\
\hline Yamal-Russia & West-Polish border & Probable & FSU-WEU & 4170 & 83 \\
\hline Shtockmanovkoye & Finland/Russia & Possible & FSU-WEU & 2268 & 25 \\
\hline Shatlyk-Turkmenistan & Erzerum-Turkey & Possible & FSU-WEU & 2700 & 31 \\
\hline Turkmenistan & Turkey-border & Possible & FSU-WEU & 1260 & 10 \\
\hline Russia (Bluestream) & Turkey & Probable & FSU-WEU & 400 & 17 \\
\hline Turkmenistan & China, Japan, S. Korea & Speculative & FSU-CPA & 7000 & 28 \\
\hline Irkutsk-Russia & China, Japan, S. Korea & Speculative & FSU-CPA & 3360 & 32 \\
\hline Yakutsk/Sakhalin-Russia & China, S.Korea, Japan & Speculative & FSU-CPA & 3900 & 20 \\
\hline Sakhalin-Russia & Niigata-Japan and to Korea & & FSU-PAO & 1300 & n.a. \\
\hline Turkmenistan & Lultan-Pakistan & Speculative & FSU-SAS & 1271 & 20 \\
\hline Turkmenistan & Multan-Pakistan & Speculative & FSU-SAS & 1500 & n.a. \\
\hline Turkmenistan & Persian Gulf & Speculative & FSU-MEA & 2000 & n.a. \\
\hline Syria & Turkey & Possible & MEA-WEU & 200 & 2 \\
\hline Qatar & Europe & Speculative & MEA-WEU & 4900 & 30 \\
\hline Iran & Europe & Possible & MEA-WEU & 4570 & 32 \\
\hline Oman & India & Speculative & MEA-SAS & 1500 & 19 \\
\hline Iran & Armenia & Possible & MEA-FSU & 160 & 2 \\
\hline Iran & Ukraine & Possible & MEA-FSU & 1060 & 25 \\
\hline Iran & Pakistan & Possible & MEA-SAS & 1600 & 9 \\
\hline Iran (Bandar Abbas) & India & Possible & MEA-SAS & 2000 & 19 \\
\hline Qatar & Pakistan & Possible & MEA-SAS & 1600 & 25 \\
\hline ASEAN countries & $\begin{array}{l}\text { China, Taiwan, Japan, } \\
\text { S. Korea }\end{array}$ & Speculative & CPA-PAO & 4300 & n.a \\
\hline $\begin{array}{l}\text { North Sea,United Kingdom } \\
\text { (Polpipe) }\end{array}$ & Niechorze-Poland & Possible & WEU-EEU & 965 & 8 \\
\hline TOTAL & & & & 61284 & $>452$ \\
\hline
\end{tabular}

a Source: Klaassen et al. (1999), CEDIGAZ (1995), McMahon (1997) and Zhao (2000).

$450 \mathrm{bcm}$ per year but around $130 \mathrm{bcm}$ are regarded as speculative. Most projects are to originate in FSU or MEA and are directed at WEU, CPA, PAO (Japan), and SAS. This planned capacity is nearly twice as high as the current interregional transmission capacity.

\subsection{The diffusion and expansion of $L N G$ terminals}

1964 marked the start of international LNG shipping with the finalization of the first LNG terminal in Algeria exporting LNG to Western Europe (EIA, 1998). Since then world trade in LNG has expanded rapidly from $2.7 \mathrm{bcm}$ in 1970 to $113 \mathrm{bcm}$ in 1998 (CEDIGAZ, 1995; BPAmoco, 1999). As in the case of interregional gas trade via pipelines, two LNG market regions can be distinguished. The Asian market features imports from the Middle East (Qatar and UAE) as well as the Pacific region (Indonesia and Malaysia). Indonesia, Malaysia, and Brunei rank as the world's biggest exporters of LNG, while Japan is the major importer of natural gas produced in the Asian Pacific rim countries. Out of $113 \mathrm{bcm}$ of global LNG trade in 1998, Japan, South Korea, and Taiwan imported $85 \mathrm{bcm}$, accounting for $75 \%$ of the

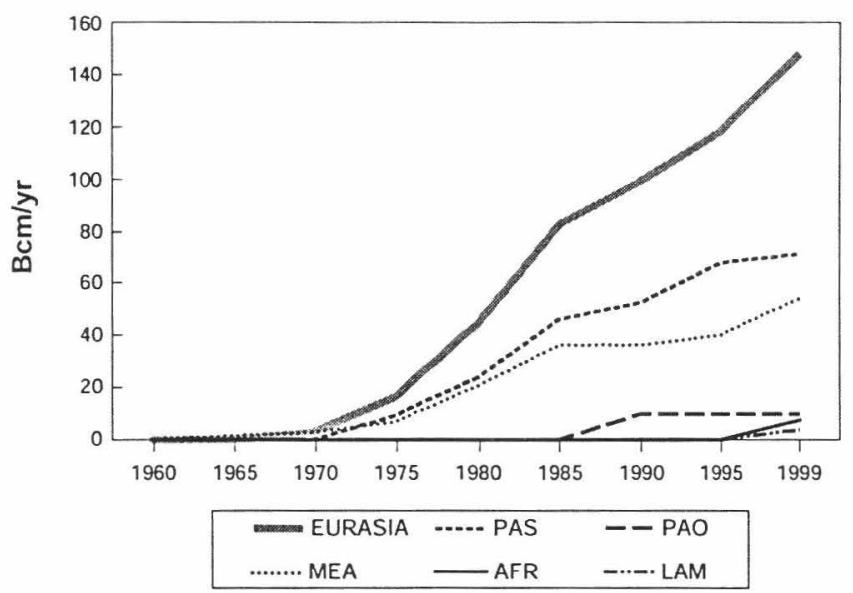

Fig. 7. The diffusion of LNG export terminals in and into Eurasia.

world total (BPAmoco, 1999). In the European market the principal supplier is Algeria, and the principal consumer is Western Europe. Some Algerian gas is also exported to the United States (BPAmoco, 1999). Fig. 7 shows the historical diffusion of LNG export terminals in or geared towards Eurasia. Although North Africa led 
Table 3

LNG capacities under construction and planned for the next five years ${ }^{\mathrm{a}}$

\begin{tabular}{|c|c|c|c|c|c|}
\hline Region & WEC & Country & Name & Capacity (bcm/year) & Year \\
\hline \multicolumn{6}{|l|}{ Under Construction } \\
\hline ASIA & PAS & Indonesia & Bontang $\mathrm{H}$ & 4 & 2000 \\
\hline MIDDLE-EAST & MEA & Oman & Oman LNG Qalhat & 9 & 2000 \\
\hline Total construction & & & & 13 & \\
\hline \multicolumn{6}{|l|}{ Planned } \\
\hline AFRICA & MEA & Egypt & Port Said & 10 & 2001 \\
\hline AUSTRALIA & $\mathrm{PAO}$ & Australia & Baya Undan & 4 & 2003 \\
\hline AUSTRALIA & $\mathrm{PAO}$ & Australia & Gorgon LNG & 12 & 2003 \\
\hline ASIA & PAS & Indonesia & Bontang I & 0 & \\
\hline ASIA & PAS & Indonesia & Irian Jaya & 8 & 2003 \\
\hline ASIA & PAS & Malaysia & MLNG 3 & 9 & 2001 \\
\hline FSU & FSU & Russia & Sakhalin II & 8 & 2005 \\
\hline MIDDLE-EAST & MEA & Qatar & Ras Laffan & 10 & 2001 \\
\hline MIDDLE-EAST & MEA & Yemen & & 7 & 2001 \\
\hline Total Planned & & & & 74 & \\
\hline \multicolumn{3}{|c|}{ PLANNED AND CONSTRUC- } & & 86 & \\
\hline
\end{tabular}

${ }^{a}$ Source: CEDIGAZ (1999).

development initially, PAS has now surpassed North Africa in terms of capacity.

Expected capacity expansions in Eurasia are shown in Table 3 . The table shows that an additional capacity of $86 \mathrm{bcm}$ is to be completed by 2005 . The above capacity expansion is reasonably in line with other projections (IEA, 1998). Most of the capacity expansion will be geared towards the Asian Pacific region (PAO, CPA, and SAS) with export capacity expanding in Australia, Indonesia, and the Middle East. Expected capacity additions in Latin America (Trinidad/Tobago) and Nigeria are partly geared towards exports to Western Europe and partly intended for North America. Canadian exports may also serve the Asian market. Available evidence shows that India (part of SAS) has plans to import around $31 \mathrm{bcm}$ of LNG, and China is preparing a tender for a terminal with a capacity of $4 \mathrm{bcm}$ per year. PAS (Thailand and Taiwan) plans terminals to import around $11 \mathrm{bcm}$ annually (Alexander's Oil and Gas Connections, 2000). Capacity expansions in Table 3 include both facilities that are actually being constructed and those that are planned. Experience shows that not all the capacity in the latter category will necessarily materialize. In summary, the LNG market appears to be booming in Asia and becoming ever more global.

\subsection{Overview of both pipeline and LNG capacity}

Table 4 summarizes for Eurasia capacities both of existing pipeline and LNG facilities that are expected to still be in operation in 2020, and of planned or proposed facilities. While a number of existing pipelines are expected to still be in service in 2020, most of the projected pipeline capacity consists of pipelines still in the planning or proposal stages. The same is true for LNG facilities. While the contribution of LNG terminals is smaller than that of pipelines, the terminals included in Table 3 are all intended for completion by 2005 . There is certainly enough time to plan and complete additional facilities, beyond those in the table, by 2020 . The estimate of existing pipeline capacity depends on the lifetime assumed and on whether lifetime extensions take place.

\section{Comparing existing plans with projections in the IIASA-WEC scenarios}

Table 5 compares interregional gas transport capacities, based on existing plans and proposals (see Table 4), with the interregional trade flows projected in 2020 for the six IIASA-WEC scenarios. In constructing the table planned import capacities of LNG have been taken as minimum constraints. Any LNG export capacity remaining has been allocated to regions where deficit import capacity was highest so at to minimize the gap between planned and proposed capacities and the expected (net) imports under the different IIASA-WEC scenarios.

For Eurasia as a whole, the $632 \mathrm{bcm}$ of planned or proposed import capacity corresponds very well with expected gas imports in the IIASA-WEC high-growth Scenario A3. The same conclusion is valid for the planned or proposed export capacity.

Looking at the results region-by-region, the first question is whether there exists for each region a robust strategy, i.e., a strategy that makes sense no matter which of the IIASA-WEC scenarios proves the best approximation 
Table 4

LNG and pipeline (net import/export) capacities planned and proposed

by $2020(\mathrm{bcm})$ in and into Eurasia ${ }^{\mathrm{a}, \mathrm{b}}$

\begin{tabular}{|c|c|c|c|c|c|}
\hline & $\begin{array}{l}\text { Still existing pipeline } \\
\text { capacity } \\
\text { In } 2020\end{array}$ & $\begin{array}{l}\text { Planned pipelines } \\
\text { In } 2020\end{array}$ & $\begin{array}{l}\text { Still existing LNG } \\
\text { terminals in } 2020\end{array}$ & $\begin{array}{l}\text { Planned and proposed } \\
\text { LNG in } 2020\end{array}$ & $\begin{array}{l}\text { Total capacity } \\
\text { In } 2020\end{array}$ \\
\hline \multicolumn{6}{|l|}{ Imports } \\
\hline WEU & $66(104)$ & 181 & 28 & 6 & 281 \\
\hline EEU & $5(37)$ & 58 & 0 & 0 & 63 \\
\hline CPA & $0(0)$ & 53 & 0 & 9 & 62 \\
\hline PAO & $0(0)$ & 20 & 10 & 73 & 103 \\
\hline SAS & $0(0)$ & 92 & 0 & 31 & 123 \\
\hline \multicolumn{6}{|l|}{ Exports } \\
\hline FSU & $52(106)$ & 239 & 0 & 8 & 299 \\
\hline MEA & $19(35)$ & 172 & 18 & 42 & 251 \\
\hline PAS & 0 & -7 & 25 & 34 & 52 \\
\hline OTHERS & 0 & 0 & 12 & 20 & 32 \\
\hline
\end{tabular}

${ }^{a}$ Note: - sign implies export.

${ }^{b}$ Data in parenthesis represent capacity with lifetime of 40 years

instead of 35 years.

Table 5

Interregional (net) gas transport capacities in 2020 based on current plans and proposals (second column), projected 2020 imports and exports in the IIASA-WEC scenarios (middle columns), and projected 2050 imports and exports in the IIASA-WEC scenarios (right column), in bcm per year

\begin{tabular}{|c|c|c|c|c|c|c|c|c|}
\hline 2020 & Total capacity & A 1 & A2 & A3 & B & $\mathrm{C} 1$ & $\mathrm{C} 2$ & $\begin{array}{l}2050 \\
\text { IIASA-WEC }\end{array}$ \\
\hline \multicolumn{9}{|c|}{ Imports } \\
\hline WEU & 281 & 286 & 270 & 328 & 254 & 212 & 195 & $93-620$ \\
\hline EEU & 63 & 84 & 81 & 120 & 71 & 84 & 84 & $36-193$ \\
\hline CPA & 62 & 30 & 4 & 84 & 1 & 46 & 31 & $0-370$ \\
\hline PAO & 103 & 89 & 120 & 93 & 115 & 69 & 68 & $0-72$ \\
\hline \multicolumn{9}{|c|}{ Exports } \\
\hline FSU & 299 & 304 & 288 & 281 & 290 & 304 & 304 & $73-682$ \\
\hline MEA & 251 & 135 & 146 & 263 & 75 & 65 & 31 & $173-955$ \\
\hline PAS & 52 & 67 & 64 & 88 & 68 & 62 & 54 & $3-49$ \\
\hline
\end{tabular}

of future developments. Absent a one-size-fits-all-scenarios robust strategy for a region, the value of this section's comparisons then lies in clarifying regional strategies for expanding gas transport capacities that match different scenarios. Does a strategy of rapidly expanding capacity, for example, constitute a bet on Scenario A3 being the best approximation of the future? Phrased slightly differently, if your strategy is one of rapidly expanding capacity, should you also be pushing on other fronts to raise the odds of a "Scenario A3" outcome, to improve the return on your investments?

For FSU, there does exist a short-term robust strategy across the IIASA-WEC scenarios - continue with current plans. As shown in Fig. 5, there is very little divergence in the scenarios' export projections through 2020 , and they match the planned/proposed FSU capacity in Table 5 very closely. After 2020 the scenarios start to diverge. Excluding the two Case $\mathrm{C}$ scenarios (which rep- resent a challenging direction that the world is so far steering well away from), the choice for FSU after 2020 will be whether to pursue an A1/A3 strategy or an A2/B strategy. The former leads to high domestic consumption, but low exports and no need for new export capacity. The latter leads to flat domestic gas consumption, but higher exports and a need for new export capacity. Of course, the choice among possible energy strategies will depend on many other considerations, including projected revenues from gas exports. These are just the implications that the choice is projected to have on the question of whether and by how much to expand export capacity in view of expected demand patterns.

For MEA, there does not appear to be a robust shortterm strategy. The choice seems to be between strategically pursuing an A3 strategy, in which case current capacity expansion plans and proposals would need to be increased only slightly, or targeting any of the other 
scenarios, in which case current plans and proposals should be scaled back - in Case B by as much as $70 \%$.

For the third exporting region, PAS, the situation is somewhat similar. The short-term choice appears to be between an A3 strategy and one targeting anything but A3. An A3 strategy would require increasing current planned and proposed additions by about $35 \mathrm{bcm}(70 \%)$. The other scenarios (excluding Case C) would require more modest increases, $10-15 \mathrm{bcm}$. Short-term choices should, however, take into account the longer-term projections. For all scenarios but A3, exports drop after 2020 and export capacity will have to be retired. A mistaken bet on A3 could thus be expensive. Even in Scenario A3 exports drop quite quickly after 2040. For PAS it may be most important to know when to stop building, rather than when to start.

For WEU, planned and proposed capacity additions for 2020 are sufficient for all but Scenario A3 (a capacity shortfall of $47 \mathrm{bcm}, 14 \%$ ) and Scenario A1 (only $5 \mathrm{bcm}$ short, or 2\%). But imports increase steeply after 2020 in all but Scenario A1 (and Case C). Thus there is time to delay planning new capacity additions and monitor how gas consumption evolves. But if trends are in the direction of Scenarios A2, A3, or B, it will be important that such monitoring leads to timely additions to planned capacity expansions.

For EEU the short-term robust strategy is to add to current plans and proposals for expansion. Exactly how much should be contingent upon how gas use evolves in the region. Particular attention should be paid to trends that correspond to Scenario A1, in which imports start to drop after 2020, or to trends that correspond to Scenario A3, which requires the greatest capacity additions, $90 \%$ above current plans and proposals by 2020 .

For PAO, the short-term choice (again excluding Case C) is between pursuing an A1/A3 strategy, for which current plans are a bit high, or an A2/B strategy, in which case some additional capacity would be needed. Note that in Fig. 4 all four of these scenarios have essentially the same gas imports in 2010, so there might be less opportunity for an adaptive approach to capacity additions as suggested for EEU. Note also that for all four of these scenarios imports start to drop immediately after 2020. While this suggests that mistaken bets on high imports might be particularly expensive, that conclusion is somewhat mitigated by the nature of this region. PAO includes both Japan and Australia, so that while net imports to the region may drop after 2030, Japan may well still be able to make good use of its import facilities for Australian gas.

As in PAO, gas imports in CPA diverge little through 2010. But CPA's divergence thereafter is even greater than PAO's. In Scenario A2 and Case B, both of which make extensive use of coal, CPA's gas imports in 2020 go almost to zero. In Scenario A3 they climb at 10\% per year. In the short term, CPA's choice appears to be between strategically pursuing an A3 strategy (adding to current capacity expansion plans and proposals) or a strategy based on anything but A3, in which case current plans and proposals should be scaled back, drastically so for Scenario A2 or Case B. As shown in Fig. 4, this will also be the longer-term choice for CPA's gas import strategy, between Scenario A3 (necessitating large capacity increases) and everything else (where imports drop essentially to zero).

The only conclusion that can be drawn from Table 5 and Fig. 4 concerning SAS is that either current plans and proposals are especially over-ambitious or the treatment of SAS gas imports in the IIASA-WEC scenarios should be revisited. On the one hand, given the lack of divergence in the IIASA-WEC scenarios through 2030, we believe that they need a closer look before they could justify conclusions concerning the relative wisdom of current SAS plans and proposals in Table 4. On the other hand, $75 \%$ of the planned additions to India's import capacity consist of piped gas from MEA and FSU, and experts have raised doubts on the economic and political wisdom of such plans (Klaassen et al., 1999).

\section{Concluding observations and discussion}

In this paper we have compared existing, planned, and proposed Eurasian infrastructures for natural gas transport, i.e., pipelines and LNG facilities, to interregional trade flows projected in the six IIASA-WEC scenarios. Our purpose was to identify capacity expansion strategies that are robust across scenarios, in cases where such strategies exist. Where they do not exist, we have sought to identify scenarios that match current plans and proposals (for regions wishing to proactively pursue policies to raise the probability of the future matching their plans) and to identify adjustments needed to make current plans consistent with different scenarios (for regions wishing to adapt their plans to raise the probability that they match the future suggested by evolving trends).

For FSU, there does exist a short-term robust strategy across the IIASA-WEC scenarios - continue with current plans. For WEU only Scenario A3 would require significant new expansion by 2020 , but trends should be monitored in anticipation of possible steep import increases after 2020 if developments follow the patterns of Scenarios A2, A3, or B. For EEU the short-term robust strategy is to add to current expansion plans and proposals contingent upon how gas use evolves in the region. Most important would be trends corresponding to Scenario A1, in which imports drop after 2020 , or to Scenario A3, which requires the largest new capacity additions. For PAS, a gas exporter, moderate additions to current plans and proposals are needed in all cases, and more substantial additions would be needed to prepare for 
a future approximating Scenario A3. CPA's choice appears to be between strategically pursuing an A3 strategy (adding to current capacity expansion plans and proposals) or a strategy based on anything but A3, in which case current plans and proposals should be scaled back. MEA has a similar situation, except from the exporter's perspective. Planned and proposed capacities are just below the export level in the high-gas Scenario A3, but are well above projected exports in all other scenarios. Note that the excessive export capacity (except for Scenario A3) planned or proposed for MEA is one reason that the import capacity planned or proposed for SAS is so much higher than the imports projected in the scenarios. Planned and proposed export capacities for MEA, and import capacities for SAS, include a number of very uncertain proposals for pipelines through Pakistan or deep under the Indian Ocean. But while these capacity projections therefore deserve to be taken with a grain of salt, so too do the import projections in the scenarios for SAS. Given their initial lack of divergence across the scenarios, we believe they need a closer look before they could justify conclusions concerning the relative wisdom of current SAS plans and proposals.

Some caveats are in order to provide perspective on the above conclusions. First, estimates of eventual capacities in 2020 based on current plans and proposals depend crucially on the (technical) lifetimes that are assumed for various infrastructures. The numbers in brackets in Table 4 correspond to 40 -year lifetimes instead of the 35-year lifetimes underlying the numbers quoted above. As is evident from the table, the extra five years sometimes make a substantial difference. Thus lifetime extensions can to some extent substitute for capacity additions. Second, there are currently no pipelines connecting the European and Asian Pacific markets, and all six IIASA-WEC scenarios assume this situation continues. That is, while the models underlying the scenarios incorporate the possibility of expanding pipeline capacities between, say, FSU and WEU, they do not include the possibility of new interregional connections between particularly FSU as an exporter and CPA, SAS, and PAO as importers. What might happen in scenarios where that constraint is relaxed? The results summarized in Figs. 4 and 5 do not provide a clear indication of what to expect. If we compare the panel for CPA gas consumption in Fig. 4 with the panel for FSU gas exports in Fig. 5, we find that the high consumption scenarios for CPA (A1 and A3) are the low export scenarios for FSU. Perhaps this means that an increased focus on gas will generally give FSU more reasons to increase consumption at home than to increase exports abroad. In that case, adding the possibility of pipelines between FSU and CPA might have no significant impact on gas trade. Alternatively, FSU exports may be low in Scenarios A1 and A3 because the worldwide focus on gas development in these scenarios (and also on oil development in Scenario A1) benefits FSU's principal export competitor (MEA) more than it benefits FSU, particularly in the Western and Eastern European markets where they compete. Perhaps, if FSU had pipelines through which to expand exports to CPA and SAS in these high-gas scenarios, it might expand its exports eastward and southward as much as MEA expands its exports northward.

In addition, our assessment of the robustness of possible strategies does not account for the political wisdom, nor for the full economic implications, of plans for exporting large amounts of gas. It is obvious that both for India and other countries (such as China and WesternEurope) political considerations and risk perceptions play an important role in determining the desirability of importing large amounts of gas from a small number of countries. These considerations go beyond the capabilities of the models used for this paper which seek to meet expected energy and gas demand at the lowest possible cost without taking into account political risk perceptions.

Moreover, the fact that we use a very high level of spatial aggregation into 11 world regions may mask important international gas trade flows that take place within these regions. Examples are flows from Australia to Japan, or from Norway to Europe or from Turkmenistan/Kazakhstan to Russia. Further disaggregation would shed more light on these international gas trade flows and might affect the conclusions on the robustness of strategies. For the FSU for example the robustness of strategies might differ between Russia and Kazakhstan or Turkmenistan. For Russia the trade-off between the benefits of domestic consumption versus additional gas export revenues might be more relevant than for countries with smaller populations and lower domestic gas demands such as Kazakhstan or Azerbaidzhan. It might therefore be worthwhile to eventually combine the broad scope of this study with a higher level of disaggregation for a specific number of countries.

Thus, while the results presented here do allow conclusions about alternative strategies in the absence of pipeline links between the eastern and western Eurasian gas markets, and while they allow us to speculate about adding pipelines, they cannot rule out much of the range of such speculations. The bottom line is that clear answers to the questions raised by possible pipeline links will require additional scenarios that examine those possibilities explicitly. Preliminary results of such new scenarios (Klaassen et al., 2000) for a modest GDP growth case (similar to the IIASA-WEC Case B) suggest that the availability of international gas pipelines between the FSU and Asia enable gas use to be significantly higher, especially in CPA and SAS. These pipelines could also largely replace LNG imports over the next 50 years. 


\section{Acknowledgements}

Comments of an anonymous referee on an earlier version of the paper are very much appreciated.

\section{References}

Alexander's Gas \& Oil Connections, 2000. Alexander's Gas \& Oil Connections; Company News E \& SE Asia. Various issues. www.gasandoil.com/goc/company/

BPAmoco, 1999. Statistical Review of World Energy 1999.

CEDIGAZ, 1993. European Natural Gas Trade by Pipelines. Cedigaz, Paris.

CEDIGAZ, 1995. Planned Gas Pipelines Around the World. Cedigaz, Paris.

CEDIGAZ, 1998. Natural Gas in the World: 1998 Survey. Cedigaz, Paris.

CEDIGAZ, 1999. Natural Gas in the World: 1998 Survey. Cedigaz, Paris.

EIA, 1998. Liquefied Natural Gas (LNG) Fact Sheet. October, Energy Information Administration, Washington, DC.

Energy Charter, 1998. Energy Transit: The Multilateral Challenge. Energy Charter Secretariat, Brussels.

IEA, 1997. Natural Gas Information 1996. OECD/International Energy Agency, Paris.

IEA, 1998. Natural Gas Pricing in Competitive Markets. OECD/Inter national Energy Agency, Paris.
Klaassen, G., Grübler, A., Schrattenholzer, L., 1999. Towards new energy infrastructures in Eurasia: a background paper. IR-99-17. IIASA, Laxenburg, Austria.

Klaassen, G., Riahi, K., Roehrl, A., 2000. Global energy scenarios, gas transmission and the environment in Asia. Paper prepared for the Northeast Asian gas and pipeline forum, 17-19 September 2000, Energy Systems Institute, Irkutsk.

Lan, Q., Paik, K.W., 1998. China Natural Gas Report. The Royal Institute of International Affairs, London.

McMahon, B., 1997. Strong demand for gas set to drive construction boom. Petroleum Economist 64 (5), 18-22.

Nakićenović, N., Grübler, A., McDonald, A., 1998. Global Energy Perspectives. Cambridge University Press, Cambridge.

Nakicenović, N., Strubegger, M., 1984. Model of European natural gas production, trade, and consumption. Working paper, IIASA, Laxenburg, Austria.

Petroleum Economist, 1996. 50 years of gas in Russia - a special supplement, Petroleum Economist 63(5), 37-79.

Stern, J.P., 1998. Competition and Liberalization in European Gas Markets: a Diversity of Models. The Royal Institute of International Affairs, London.

Stern, J.P., 1999. Soviet and Russian Gas: the origins and evolution of Gazproms's export strategy. In: Mabro, R., Wybrew-Bond, A. (Eds.), Gas to Europe, the Strategies of Four Major Suppliers. Oxford University Press, Oxford, pp. 135-199.

Zhao, J., 2000. Diffusion, costs and learning of developing international gas transmission lines. IR-00-054. IIASA, Laxenburg, Austria. 
